\title{
Prevalence and correlates of depressive symptoms in older people in the West Bank, Palestine: cross-sectional study
}

Manal Badrasawi ${ }^{1}$ and Souzan Zidan ${ }^{1}$

${ }^{1}$ Nutrition and Food Technology Department, Faculty of Agriculture and Veterinary Medicine, An-Najah National University, Nablus, Palestine. (Correspondence to: Manal Badrasawi: manalpharmacist@gmail.com).

\begin{abstract}
Background: Depressive disorders in elderly people can affect their cognitive and physical abilities and nutritional status. Aims: This study aimed to determine the prevalence of depressive disorders in older Palestinians and its relationship with nutritional, functional and cognitive status.

Methods: A cross-sectional study was conducted among Palestinians $>60$ years living in Hebron, West Bank from September 2017 to March 2018. An interview-based questionnaire was used to obtain information on sociodemographic characteristics, nutritional habits, anthropometric measurements, cognitive function (using the Montreal cognitive assessment tool), and functional status (using activities of daily living and instrumental activities of daily living scales). The presence of depressive symptoms was determined using the geriatric depression scale: a score $\geq 5$ indicated depressive symptoms.
\end{abstract}

Results: A total of 291 participants were included in the study. Mean age was 70.4 (SD 7.0) years, range 60-100. The prevalence of depressive symptoms was $51.9 \%$. Depression was significantly associated with marital status (being single), low educational and income level, unemployment, and inability to write and make calculations. The presence of depressive disorders was also significantly associated with lower scores on the instrumental activities of daily living scale and the Montreal cognitive assessment tool, and with hypercholesterolaemia, chewing and swallowing difficulties and lack of appetite.

Conclusion: A considerable percentage of older Palestinian adults had depressive symptoms. There is a need to screen and treat depressive symptoms among older Palestinian adults to prevent their progression to severe mental health problems. Keywords: depression, aged, prevalence, nutritional status, functional status, cognition, Palestine.

Citation: Badrasawi M; Zidan S. Prevalence and correlates of depressive symptoms in older people in the West Bank, Palestine: cross-sectional study. East Mediterr Health J. 2021;27(3):260-268. https://doi.org/10.26719/2021.27.3.260

Received: 28/11/19; accepted: 15/03/20

Copyright (C) World Health Organization (WHO) 2021. Open Access. Some rights reserved. This work is available under the CC BY-NC-SA 3.0 IGO license (https://creativecommons.org/licenses/by-nc-sa/3.o/igo).

\section{Introduction}

Depression affects $7 \%$ of the general elderly population (1). The development of depression in older adults may be attributable to a reduction in mental, cognitive and physical abilities, increased probability of death among their friends or loved ones, retirement and loss of communication with people. Symptoms including fatigue, anxiety, insomnia, feelings of hopelessness, permanent sadness, anxiety, low energy, aches and pains, and suicidal thoughts may all be signals of depression in later age (2).

Although depression is the most widespread psychiatric disorder among elderly people, it is usually misdiagnosed and undertreated (3). This could be as a result of the misconception that depression is part of the ageing process rather than a treatable disorder. Depression increases dependence on others and reduces an individual's quality of life. If depression is left untreated, there will be considerable social and clinical effects on the lives of elderly people (4).

Diagnosis of depression in older people is often difficult. The elderly person and his/her family members may deny the possibility of depression and if he/she has cognitive impairment, eliciting a history may be complicated. Signs and symptoms of depression among elderly individuals are also distinct from depression in other periods of adulthood. The elderly often present with somatic or non-specific symptoms rather than the typical symptoms of depression, such as low energy, fatigue, reduction in physical movements and cognitive deficits (5).

Studies have assessed the link between depression and body weight. However, the findings differ: some studies have reported a positive association (6), some a negative association (7) and some have found no association (8). These findings indicate that not all individuals who are overweight or obese have psychological problems such as depression and there could be specific factors predisposing certain people to depression. For example, sociodemographic factors are possible mediators and moderators of the association between body weight and depression which may explain the inconsistent results.

In the past two decades, life expectancy at birth in Palestine has increased considerably, which has led to an increase in the elderly population. The number of older adults aged more than 60 years in mid-2019 was 257151 
(5\% of the population): 169503 people $(6 \%)$ in the West Bank and 87648 (4\%) in Gaza Strip (9). This proportion of elderly people in the population is expected to grow even more in the next decade (9).

To our knowledge, no research has been done on depressive disorders in elderly Palestinians. Therefore, the main aim of our study was to screen older Palestinian adults for depressive disorders and to assess the associated risk factors, including nutritional, functional and cognitive status.

\section{Methods}

\section{Study design, setting and sample}

This was a cross-sectional study of elderly people in Hebron, West Bank. Hebron district consists of the main city of Hebron, two refugee camps and a large number of villages. We randomly selected one camp, two villages - one from the south and one from the north - and three different areas in the city to represent the study population.

We used G power software, version 3.1.9.7 to calculate the sample size based on the percentage of older adults in Palestine (6\%), a $5 \%$ margin of error and $95 \%$ confidence level. The sample size calculated was 280 participants, and assuming a $5 \%$ drop-out, the required sample size was 294 participants. We used purposive sampling to select participants. Inclusion criteria were individuals aged 60 years or more who lived in the selected areas and agreed to take part in the study. Exclusion criteria were the presence of acute illness on the day of data collection (as reported by the potential participant) and severe hearing problems that prevented communication with the research team.

After we had selected the areas, the research team contacted the local committee for each place and they helped us to approach the older adults. The committee differed from place to place, for example, for the camps, it was a committee of the refugee affairs department, and for villages, it was the village municipality. The response rate was $94 \%$ (very few people did not agree to participate)

\section{Data collection}

Our data collection team was composed of five nutritionists trained to take anthropometric measurements and assess body composition, and to do physical function tests. The team collected data from September 2017 to March 2018. It was difficult to collect data from older adults during the winter when the weather was very cold (December-February) so we stopped the data collection if the weather was very cold. In addition, because of the large amount of data collected, we could only assess about 5-7 participants a day. They briefed the participants on the purpose of the study and gave them an information sheet with details about the study. They then interviewed the participants in order to complete the questionnaires.

\section{Instruments}

We used a questionnaire to collect data on sociodemographic characteristics, medical history and dietary habits. Items on sociodemographic data included: sex, marital status, educational level, monthly income, working status and living status (living alone or with their family). For medical history, we asked about the self-reported presence of 15 chronic diseases (hypertension, hypercholesterolaemia, diabetes, stroke, osteoarthritis, heart disease, glaucoma, renal disease, asthma, chronic obstructive pulmonary disease, gout, hip fracture, constipation, gastric ulcer and cancer), and on previous surgery, if any (number of surgical operations, types and dates). In addition, the questionnaire included questions on history of falls, how many and where, and if the fall resulted in hospital admission for a fracture. We also asked about smoking status. Dietary habits were self-reported by the participants. Questions included total number of meals a day, main meals and snacks per day, and the time of the last meal and first meal of the day to estimate the period of overnight fasting.

We also assessed nutritional status, mental health, cognitive function and physical function status.

To assess nutritional status, we used the mini nutritional assessment tool which is a reliable, feasible and non-invasive screening test for evaluating of nutritional status in elderly people (10). This questionnaire has 18 different questions, such as experiencing psychological stress or acute disease in the past 3 months, weight loss in the past 3 months, and amount of fluids (e.g. water, juice, coffee, tea and milk) drunk a day. We then classified the participants into three categories: malnutrition (score < 17); at risk of malnutrition (score 17-23); adequate nutrition (score 24-30) (11).

We also assessed nutritional status from anthropometric measurements and dietary habits. The data collection team took weight, height and mid-upper arm circumference measurements according to standard anthropometric procedures (12). We calculated body mass index - weight in kilograms divided by height in metres squared $\left(\mathrm{kg} / \mathrm{m}^{2}\right)$. We measured the mid upper arm circumference on the right arm using a measuring tape. We defined muscle wasting as mid upper arm circumference $<23 \mathrm{~cm}$ for men and $<22 \mathrm{~cm}$ for women (12).

Many screening instruments are available to detect depression in elderly people. One of the most commonly used is the 15-item geriatric depression scale. We used the validated Arabic version of this scale as the study instrument because it has been shown to have high sensitivity (83\%) and specificity (91\%) (10). The scale has 15 short questions (yes/no) on symptoms of depression. One point is assigned to each answer and the cumulative score is rated on a scoring grid. A score of $<5$ indicates absence of depression and a score of $\geq 5$ indicates a high risk of a depressive disorder (10).

We also used a validated Arabic version of Montreal cognitive assessment - basic, which has an adequate 
test-retest reliability, to detect mild cognitive impairment (13). This tool has a sensitivity of $92.3 \%$ and specificity of $85.7 \%$. The Montreal cognitive assessment - basic assesses similar cognitive domains as the original instrument: executive function, language, orientation, simple mathematical calculations, conceptual thinking, memory, visual perception, attention and concentration. The questionnaire takes about 15 minutes to complete. It is scored on 30 points: scores $\geq 26$ are considered normal, scores $<26$ indicate mild cognitive impairment (13).

We assessed physical function with a functional status assessment using the activities of daily living and instrumental activities of daily living. The activity of daily living was assessed using the Katz index scale (14) and instrumental activity of daily living was assessed using the Lawton scale to assess the independence of daily living activity (15).

\section{Statistical analysis}

We used SPSS, version 21 to analyse the data. We set a $5 \%$ alpha level and $80 \%$ power in all of the statistical tests. We calculated the means and the standard deviations (SDs) for continuous variables, and percentages for categorical variables. To assess the categorical variables associated with depressive symptoms, we used the chi-squared test. Marital status and educational level did not fulfil the assumption of chi-squared test so we used the Fisher exact test. We used the independent sample t-test to examine differences in the means of the continuous variables.

\section{Ethical considerations}

The study protocol was approved by the Deanship of Scientific Research Ethical Committee at Palestine Polytechnic University committee (reference number (2018)30|كع. We obtained informed written and verbal consent $d$ from all participants before data collection.

\section{Results}

We approached 350 elderly people, of whom 330 were invited to participate in the study and gave their verbal consent to participate. Of these, 291 were included in the final analysis; 39 participants were excluded because primary data were missing.

\section{Sociodemographic characteristics}

Table 1 shows the sociodemographic characteristics of our sample. The mean age of the participants was 70.4 (SD 7.0) years, range 60-100 years. Of the 291 participants, $53.6 \%$ were women and $46.3 \%$ had a primary school education, while $23.0 \%$ had had no formal education. Most of the participants were married $(68.3 \%)$, were unemployed $(60.3 \%)$, were living with their family $(79.3 \%)$ and were non-smokers $(62.2 \%)$. Most reported that they could read, write, and make calculations with numbers, $67.5 \%, 62.6 \%$ and $60.7 \%$, respectively.

\begin{tabular}{|c|c|c|c|}
\hline \multicolumn{4}{|c|}{$\begin{array}{l}\text { Table } 1 \text { Sociodemographic characteristics of older adults } \\
\text { according to sex }\end{array}$} \\
\hline \multirow[t]{2}{*}{ Variable } & Males & Females & Total \\
\hline & No. (\%) & No. (\%) & No. (\%) \\
\hline \multicolumn{4}{|l|}{ Age (years) } \\
\hline$\leq 70$ & $78(57.8)$ & $88(56.4)$ & $166(57.0)$ \\
\hline$>70$ & $57(42.2)$ & $68(43.6)$ & $125(43.0)$ \\
\hline \multicolumn{4}{|l|}{ Marital status } \\
\hline Single & $10(7.4)$ & $20(12.9)$ & $30(10.3)$ \\
\hline Married & $117(86.7)$ & $81(52.3)$ & $198(68.3)$ \\
\hline Divorced & $0(0.0)$ & $3(1.9)$ & $3(1.0)$ \\
\hline Widowed & $8(5.9)$ & $51(32.9)$ & $59(20.3)$ \\
\hline \multicolumn{4}{|l|}{ Educational level } \\
\hline Primary & $59(44.4)$ & $74(48.1)$ & $133(46.3)$ \\
\hline Secondary & $28(21.1)$ & $21(13.6)$ & $49(17.1)$ \\
\hline Diploma & $11(8.3)$ & $4(2.6)$ & $15(5.2)$ \\
\hline University & $21(15.8)$ & $3(1.9)$ & $24(8.4)$ \\
\hline No formal education & $14(10.5)$ & $52(33.8)$ & $66(23.0)$ \\
\hline \multicolumn{4}{|l|}{ Living status } \\
\hline Living with family & $111(82.2)$ & $119(76.8)$ & $230(79.3)$ \\
\hline Living alone & $24(17.8)$ & $36(23.2)$ & $60(20.7)$ \\
\hline \multicolumn{4}{|l|}{ Employment status } \\
\hline Employed & $41(30.4)$ & $11(7.1)$ & $52(17.9)$ \\
\hline Part-time job & $15(11.1)$ & $16(10.3)$ & $31(10.7)$ \\
\hline Unemployed & $54(40.0)$ & $121(78.1)$ & $175(60.3)$ \\
\hline Retired & $25(18.5)$ & $7(4.5)$ & $32(11.0)$ \\
\hline \multicolumn{4}{|l|}{$\begin{array}{l}\text { Monthly income } \\
\text { (Israeli shekel) }^{a}\end{array}$} \\
\hline$<1500$ & $37(34.6)$ & $60(47.6)$ & $97(41.6)$ \\
\hline $1501-3000$ & $51(47.7)$ & $48(38.1)$ & $99(42.5)$ \\
\hline$>3001$ & $19(17.8)$ & $18(14.3)$ & $37(15.9)$ \\
\hline
\end{tabular}

aUS\$1 $\approx 3.5$ Israeli shekels.

\section{Medical history}

Cardiovascular diseases were prevalent among the participants; nearly half $(48.5 \%)$ had hypertension, while $35.2 \%$ had osteoarthritis, and $29.6 \%$ had diabetes (Figure 1). Only $2.4 \%$ reported that they had cancer. A large proportion of our participants (36.7\%) had dentures, $15.9 \%$ lacked an appetite and $13.7 \%$ had difficulty chewing.

\section{Nutritional status}

Figure 2 shows that a considerable proportion of our sample were overweight $(34.4 \%)$ and obese $(46.0 \%)$. According to the mini nutrition assessment, $41.9 \%$ (122/291) of the participants were well-nourished, $27.8 \%(81 / 291)$ were at risk of malnutrition and $30.2 \%$ (88/291) were malnourished. The mean scores in the mini nutritional assessment tool, indicate that our sample was malnourished, mean score 11.9 (SD 2.1) (Table 2); women had significantly lower mean scores than men, 11.5 (SD 2.3) and 12.4 (SD1.7), respectively $(P<0.001)$. 


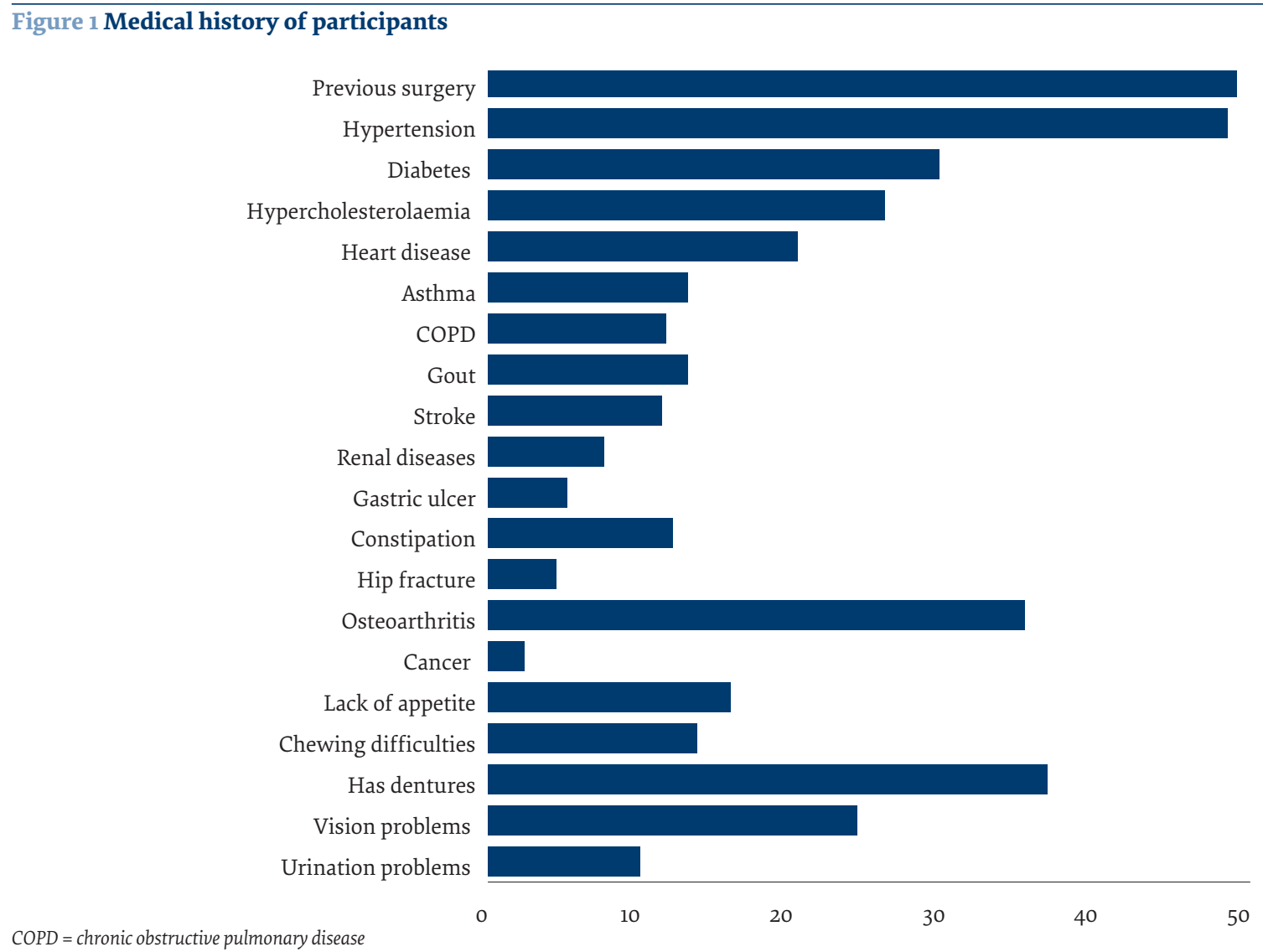

\section{Functional and cognitive status}

Men had a significantly higher mean score for cognitive function than women $(P<0.001$; Table 2). However, there were no significant differences between men and women for functional status as indicated by the mean scores on the actvity of daily living scale and instrumental activity of daily living scale.

\section{Depression and sociodemographic characteristics}

The prevalence of depressive disorders in our sample was $51.9 \%$ (151/291); of these $48.3 \%$ were men and $57.6 \%$ were women (Table 3). Depression was significantly associated with marital status (single people were more likely to have depression), lower educational level, being employed, lower income, and being unable to write and make calculations $(P<0.05$; Table 3$)$. Furthermore, a significantly higher prevalence of depressive symptoms was reported in participants with hypercholesterolemia (64.0\% (48/76) compared with participates with normal cholesterol levels (47.9\% (103/215); $P<0.05)$. Similarly, $72.5 \%(29 / 40)$ of participants with chewing problems also reported depressive symptoms, while among participants without chewing problems, only $48.8 \%$ (122/250) reported depressive symptoms $(P<0.05)$. In addition, $73.9 \%(34 / 46)$ of participants who lacked an appetite had depressive symptoms and while only $47.8 \%$ (117/245) of participants with a normal appetite had depressive symptoms was $(P<0.05)$.

\section{Relationship between nutritional, functional, cognitive and dietary status}

The mean scores on the instrumental activity of daily living scale were lower in individuals with depressive disorders (5.15 (SD 2.29)) than those without (6.37 (SD 1.89), $P<0.002$ ). Furthermore, the scores on the Montreal Cognitive Assessment were significantly lower in individuals with depressive symptoms: (17.10 (SD 4.41)) compared

\section{Figure 2 Weight categories of participants based on body} mass index, according to sex

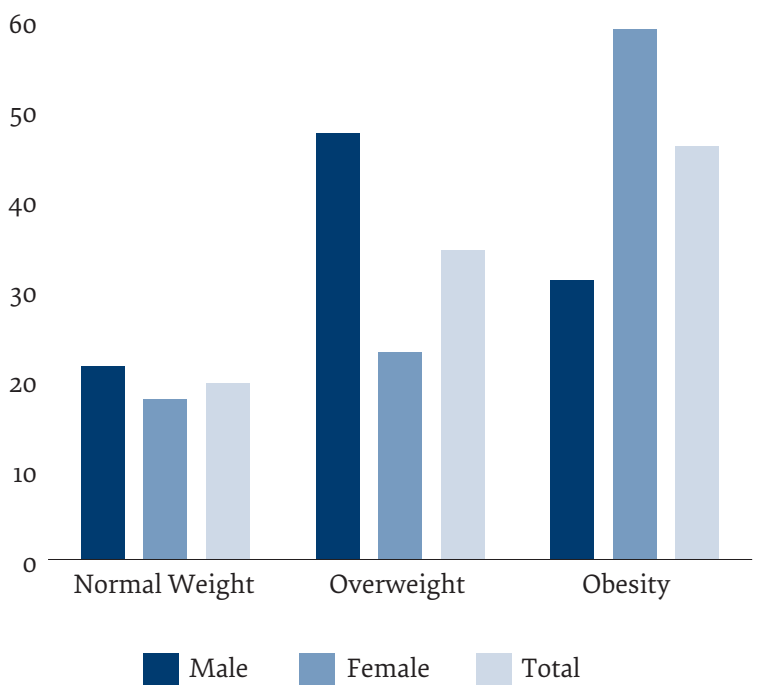


Table 2 Cognitive, functional and nutritional status of older adults according to sex

\begin{tabular}{lcccc} 
Tool & $\begin{array}{c}\text { Total } \\
\text { Mean (SD) }\end{array}$ & $\begin{array}{c}\text { Males } \\
\text { Mean (SD) }\end{array}$ & $\begin{array}{c}\text { Females } \\
\text { Mean (SD) }\end{array}$ & P-value \\
Montreal cognitive assessment & $18.8(4.9)$ & $20.3(4.5)$ & $17.6(4.8)$ & $<0.001$ \\
Actvity of daily living & $3.7(2.7)$ & $3.8(2.7)$ & $3.7(2.6)$ & 0.93 \\
Instrumental activity of daily living & $5.7(2.2)$ & $5.9(1.9)$ & $5.5(2.4)$ & 0.19 \\
Mini nutritional assessment & $11.9(2.1)$ & $12.4(1.7)$ & $11.5(2.3)$ & 0.001 \\
\hline
\end{tabular}

Table 3 Sociodemographic characteristics according to depressive disorders

\begin{tabular}{|c|c|c|c|}
\hline \multirow[t]{2}{*}{ Variable } & $\begin{array}{l}\text { Without depressive disorders } \\
\qquad(n=140)\end{array}$ & $\begin{array}{l}\text { With depressive disorders } \\
\qquad(n=151)\end{array}$ & P-value \\
\hline & No. (\%) & No. (\%) & \\
\hline \multicolumn{4}{|l|}{ Age (years) } \\
\hline$\leq 70$ & $88(62.9)$ & $78(51.7)$ & \multirow[t]{2}{*}{0.054} \\
\hline$>70$ & $52(37.1)$ & $73(48.3)$ & \\
\hline \multicolumn{4}{|l|}{ Sex } \\
\hline Male & $71(50.7)$ & $64(42.4)$ & \multirow[t]{2}{*}{0.096} \\
\hline Female & $69(49.3)$ & $87(57.6)$ & \\
\hline \multicolumn{4}{|l|}{ Marital status } \\
\hline Single & $5(3.6)$ & $25(16.7)$ & \multirow[t]{4}{*}{$<0.001$} \\
\hline Married & $107(76.4)$ & $91(60.7)$ & \\
\hline Divorced & $1(0.7)$ & $2(1.3)$ & \\
\hline Widowed & $27(19.3)$ & $32(21.3)$ & \\
\hline \multicolumn{4}{|l|}{ Education } \\
\hline Primary & $55(39.9)$ & $78(52.3)$ & \multirow[t]{5}{*}{$<0.001$} \\
\hline Secondary & $21(15.2)$ & $28(18.8)$ & \\
\hline Diploma & $12(8.7)$ & $3(2.0)$ & \\
\hline University & $22(15.9)$ & $2(1.3)$ & \\
\hline No formal education & $28(20.3)$ & $38(25.5)$ & \\
\hline \multicolumn{4}{|l|}{ Living status } \\
\hline Living with family & $114(81.4)$ & $116(77.3)$ & \multirow[t]{2}{*}{0.390} \\
\hline Living alone & $26(18.6)$ & $34(22.7)$ & \\
\hline \multicolumn{4}{|l|}{ Employment } \\
\hline Employed & $24(17.1)$ & $28(18.7)$ & \multirow[t]{4}{*}{$<0.001$} \\
\hline Part-time job & $7(5.0)$ & $24(16.0)$ & \\
\hline Unemployed & $82(58.6)$ & $93(62.0)$ & \\
\hline Retired & $27(19.3)$ & $5(3.3)$ & \\
\hline \multicolumn{4}{|c|}{ Monthly income (Israeli shekel) } \\
\hline$<1500$ & $30(28.6)$ & $67(52.3)$ & \multirow[t]{3}{*}{0.018} \\
\hline $1501-3000$ & $52(49.5)$ & $47(36.7)$ & \\
\hline$>3001$ & $23(21.9)$ & $14(10.9)$ & \\
\hline \multicolumn{4}{|l|}{ Able to read } \\
\hline Yes & $100(71.4)$ & $95(63.8)$ & \multirow[t]{2}{*}{0.164} \\
\hline No & $40(28.6)$ & $54(36.2)$ & \\
\hline \multicolumn{4}{|l|}{ Able to write } \\
\hline Yes & $96(68.6)$ & $85(57.0)$ & \multirow[t]{2}{*}{0.028} \\
\hline No & $44(31.4)$ & $64(43.0)$ & \\
\hline \multicolumn{4}{|l|}{ Calculating ability } \\
\hline Yes & $96(68.6)$ & $80(53.3)$ & \multirow[t]{2}{*}{$<0.001$} \\
\hline No & $44(31.4)$ & $70(46.7)$ & \\
\hline
\end{tabular}

Values are missing for some variables. 
with those without depressive symptoms (20.74 (SD 4.75); $P<0.001)$. In addition, the number of meals eaten a day was significantly lower in people with depression (2.22 (SD 0.75)) than in people without depression (3.49 (SD 1.20), $P=0.021)$. Furthermore, malnutrition (19.9\%) and obesity (52.3\%) were more common in participants with depressive disorder $(P<0.05)$, as shown in Table 4.

\section{Discussion}

We evaluated the prevalence of depressive disorders in Palestinians $>60$ years and its relationship with sociodemographic characteristics, dietary habits, body weight, and functional, cognitive and nutritional status.

The prevalence of depressive disorder was 51.9\%. This prevalence is higher than that found in a European population-based study that reported a rate of $17.3 \%$ in Ireland, $17.5 \%$ in Netherlands, $23.5 \%$ in Germany, $19.4 \%$ England and 36.5\% in Italy (16). A Lebanese study reported a lifetime prevalence of depression of 9.3\% among elderly people (17). Differences in the rate of depressive disorders can be attributed to variations in the study methods, and differences in socioeconomic characteristics, cultural background and societal circumstances.

In our study, the prevalence of depression was significantly higher among the elderly respondents who were unemployed. This finding was consistent with a study in Puducherry, India (18). This finding can be explained by the fact that unemployment was linked with low income which in turn was correlated with depression (18).

Furthermore, our study found that the prevalence of depressive disorder in elderly people was significantly correlated with marital status. This result is supported by the Indian study, where the prevalence of depression was significantly higher among single and widowed elderly people (18). In our study, the prevalence of depression was significantly higher among women, which is similar to the Indian study which also found significant difference in the prevalence of depression by sex (18).

Depressive disorder was also significantly more prevalent among those with a low educational level, which concurs with the findings of a study in Malaysia (19). Lower education plays an important role in late-life depressive disorders, which is related to low socioeconomic status. Older adults with a lower education level tend to earn less than their better educated counterparts. Educationrelated financial issues are risk factors for depression among older adults (20).

In our study, chronic diseases such as hypercholesterolaemia were significantly associated with depressive disorders in our elderly participants. This finding concurs with previous studies where a strong correlation between depression and the presence of hypercholesterolaemia was seen $(21,22)$. Evidence suggests that depression has pathophysiological and behavioural influences on the cardiovascular system. Firstly, depression has been linked to unhealthy lifestyles, including smoking, unhealthy dietary habits, physical inactivity and low adherence to medical regimens, which may in turn increase the risk of hypercholesterolemia (3). Secondly, pathophysiological influences assume that many bioclinical factors, such as psychological, genetic and biochemical factors, may interact with depression and increase the likelihood of the development of cardiovascular diseases and hypercholesterolaemia (23).

We found that depression was significantly associated with a lack of appetite, and swallowing and chewing difficulties. A study in the United States of America also found a significant association between depression and appetite (24). The lack of appetite from depression is often combined with other factors such as widowhood, reduced social networks and a reduction in the variety of food or institutionalization, which are common experiences for older adults (24). Unlike other studies $(19,25)$, our study suggests that depression is not correlated with hypertension and osteoarthritis.

We found a significant association between obesity and depressive symptoms, which was inconsistent with findings from previous studies $(26,27)$. Both studies revealed, the prevalence of depression was lower among obese men and women as compared to those with normal weight. Although one study found a $U$ shaped relationship between BMI and depression among young

\begin{tabular}{|c|c|c|c|}
\hline \multirow[t]{2}{*}{ Variable } & $\begin{array}{l}\text { Without depressive disorders } \\
\qquad(n=140)\end{array}$ & $\begin{array}{l}\text { With depressive disorder } \\
\text { ( } n=151)\end{array}$ & \multirow[t]{2}{*}{ P-value } \\
\hline & No. (\%) & No. (\%) & \\
\hline \multicolumn{4}{|l|}{ BMI category } \\
\hline Normal weight & $25(17.9)$ & $32(21.2)$ & \multirow[t]{3}{*}{$<0.001$} \\
\hline Overweight & $60(42.9)$ & $40(26.5)$ & \\
\hline Obese & $55(39.3)$ & $79(52.3)$ & \\
\hline \multicolumn{4}{|c|}{ Mini nutritional assessment category } \\
\hline Well-nourished & $50(35.7)$ & $72(47.7)$ & \multirow[t]{3}{*}{$<0.0001$} \\
\hline Risk of malnutrition & $32(22.9)$ & $49(32.5)$ & \\
\hline Malnourished & $58(41.4)$ & $30(19.9)$ & \\
\hline
\end{tabular}


adult, the relationship was not significant in older adults, which may be explained by differences between young and elderly people in their interest in body image (26). The significant relationship found in our study may be because of the presence of functional limitations due to obesity, which can adversely affect the quality of life and may increase the depressive symptoms.

We also found a correlation between the geriatric depression scale and the mini nutritional assessment. Depression was significantly more common among elderly people who were at risk of malnutrition. This finding concurs with other studies $(28,29)$. Depression results in decreased food intake and loss of appetite and thus leads to weight loss. Alterations in eating habits and appetite is an important criterion for diagnosis of depression (30). In addition, ageing is associated with atrophic inflammation of the gastrointestinal tract, which in turn results in malabsorption and decrease in appetite, and consequently malnutrition (30).

Functional status was significantly associated with depressive disorders in our sample of elderly people, which is supported by another study (19). The use of assistive devices and environmental alterations can improve functional status via better performance in instrumental activities of daily living, which can minimize the risk of depression (31). It has been reported that the likelihood of depressive disorders in older adults is greater if functional limitations are combined with chronic diseases (32).

Our findings show that depressive disorders in older people have an adverse effect on cognitive function and were associated with a significant decrease in the mean values of total score on the Montreal cognitive assessment. A causal correlation between these two factors is still ambiguous because their prevalence increases with age and few prospective studies have been conducted (33). Some studies have reported that depression does not lead to cognitive decline (34,35), while others have found that depression is a risk factor for incident dementia (36).

Our study has several limitations. First, as this was a cross-sectional study, no causal relationships can be inferred for the association found between certain variables and depression. Second, the data collected were self-reported. This may lead to misreporting and recall bias because of the nature of the study and the older age of the participants. Third, we did not directly observe dietary patterns which may have an effect on depression. Fourth, the study only included one region in Palestine. Even though Palestine is small country, we have some differences in the lifestyle and social life between the north and south of the country, and it would be of interest to understand if these differences affect the incidence of depression. Nonetheless, our study is the first of its kind to explore the prevalence of depressive disorders among elderly people in Palestine and the associated factors. Future studies should focus on clarifying the causal relationship, consider the age of subjects (e.g. over 75 , over 85 ) and assess nutritional and social status for a better understanding of depression in elderly people.

To conclude, a considerable proportion of elderly Palestinians had depressive disorders. The presence of these disorders was closely related to lower scores on the instrumental activities of daily living, higher scores on the Montreal Cognitive Assessment, chewing difficulties, lack of appetite, swallowing problems and chronic diseases such as hypercholesterolaemia. Primary care providers need to be vigilant in diagnosing and treating depression in elderly patients in order to increase quality of life and prevent mental health deterioration. Our findings can serve as baseline data to develop effective community programmes to assist in the management of common mental health disorders, mainly depression, in older adults.

Funding: None.

Competing interests: None declared.

\section{Prévalence et corrélats des symptômes dépressifs chez les personnes âgées en Cisjordanie (Palestine) : étude transversale \\ Résumé}

Contexte : Les troubles dépressifs chez les personnes âgées peuvent affecter leurs capacités cognitives et physiques ainsi que leur état nutritionnel.

Objectifs : La présente étude visait à déterminer la prévalence des troubles dépressifs chez les Palestiniens âgés et sa relation avec l'état nutritionnel, fonctionnel et cognitif.

Méthodes: Une étude transversale a été menée auprès de Palestiniens âgés de plus de 60 ans vivant à Hébron, en Cisjordanie, de septembre 2017 à mars 2018. Un questionnaire d'entretien a été utilisé pour obtenir des informations sur les caractéristiques sociodémographiques, les habitudes nutritionnelles, les mesures anthropométriques, la fonction cognitive (de l'outil d'évaluation cognitive de Montréal) et le statut fonctionnel (à l'aide des activités de la vie quotidienne et des activités instrumentales des échelles de la vie quotidienne). La présence de symptômes dépressifs a été déterminée à l'aide de l'échelle de dépression gériatrique : un score supérieur ou égal à 5 indique des symptômes dépressifs.

Résultats : Au total, 291 participants ont été inclus dans l'étude. Lâge moyen était de 70,4 ans (écart type 7,0), variant entre 60 et 100 ans. La prévalence des symptômes dépressifs était de 51,9\%. La dépression était associée de manière significative au statut marital (célibat), au faible niveau d'éducation et de revenu, au chômage et à l'incapacité d'écrire et de faire des calculs. La présence de troubles dépressifs était également significativement associée à des scores plus 
faibles sur l'échelle des activités instrumentales de la vie quotidienne et l'outil d'évaluation cognitive de Montréal, ainsi qu'à une hypercholestérolémie, des difficultés de mastication et de déglutition et à un manque d'appétit.

Conclusion : Un pourcentage considérable des adultes palestiniens âgés présentaient des symptômes dépressifs. Il est nécessaire de dépister et de traiter les symptômes dépressifs chez ces derniers pour prévenir leur évolution vers des problèmes de santé mentale graves.

معدل انتشار أعر اض الاكتئاب بين المسنين في الضفة الغربية، فلسطين والعوامل المرتبطة بذلك: دراسة مقطعية منال بدرا ساوي، سوزان زيدان

الخلاصة:

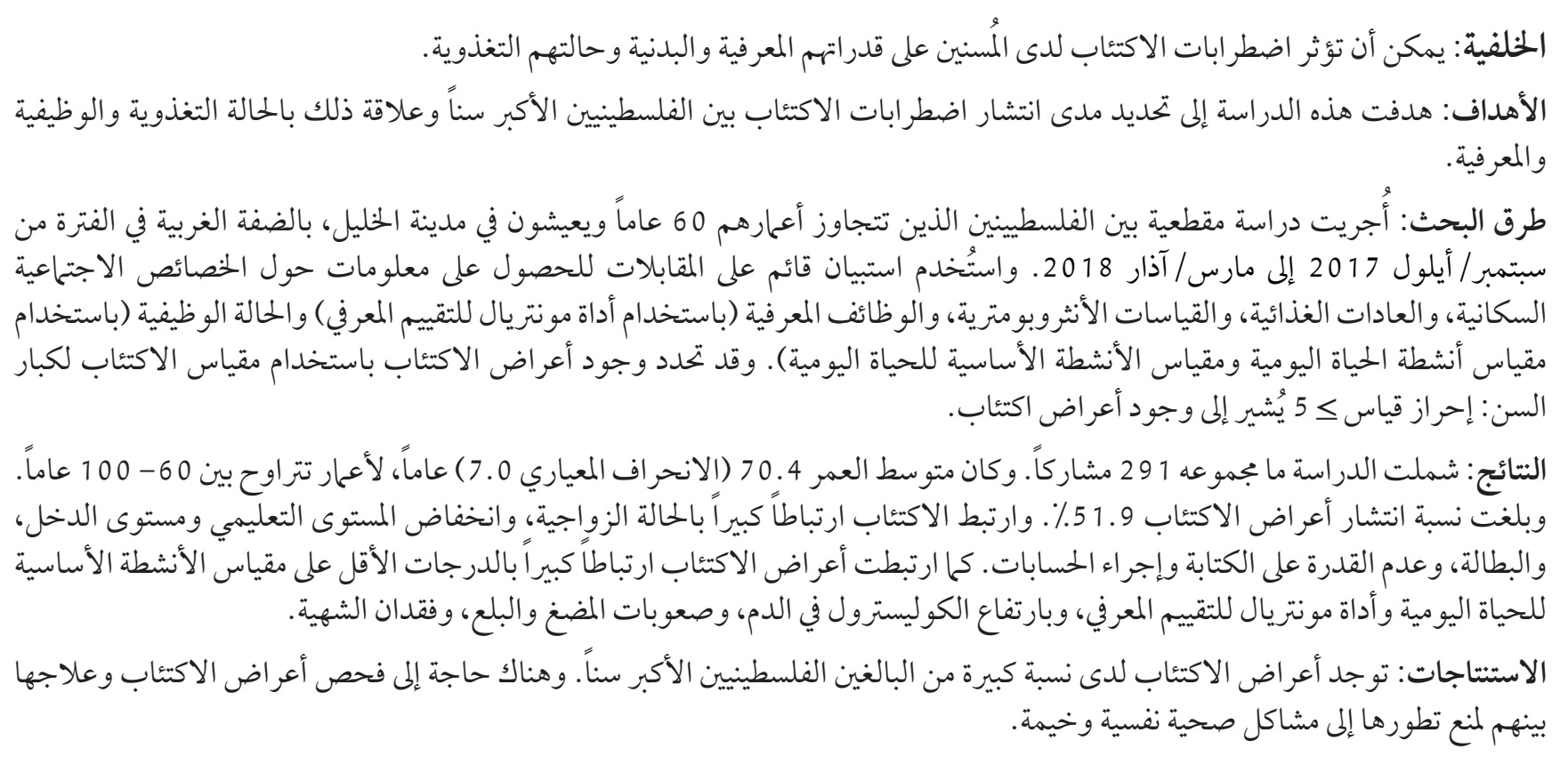

\section{References}

1. Mental health of older adults. Geneva: World Health Organization: 2017 (http://www.who.int/mediacentre/factsheets/fs381/en/, accessed 2 November 2019).

2. Allen J. Depression in assisted living. Geriatr Nurs. 2015;36(1):78-80. https://doi.org/10.1016/j.gerinurse.2014.12.005

3. Radhakrishnan S, Nayeem A. Prevalence of depression among geriatric population in a rural area in Tamilnadu. Int J Nutr Pharmacol Neurol Dis. 2013;3(3):309-12. https://doi.org/10.4103/2231-0738.114880

4. Rajkumar AP, Thangadurai P, Senthilkumar P, Gayathri K, Prince M, Jacob KS. Nature, prevalence and factors associated with depression among the elderly in a rural south Indian community. Int Psychogeriatr. 2009;21(2):372-8. https://doi.org/10.1017/ S1041610209008527

5. Evans M, Mottram P. Diagnosis of depression in elderly patients. Adv Psychiatr Treat. 2000;6(1):49-56. https://doi.org/10.1192/ apt.6.1.49

6. McCrea RI, Berger YG, King KB. Body mass index and common mental disorders exploring the shape of the association and its moderation by age, gender and education. Int J Obes. 2012;36(3):414-21. https://doi.org/10.1038/ijo.2011.65

7. Palinkas LA, Wingard DL, Barrett-Connor E. Depressive symptoms in the overweight and obese older adults: a test of the "jolly fat' hypothesis. J Psychosom Res. 1996;40(1):59-66. https://doi.org/10.1016/0022-3999(95)00542-0

8. Forman-Hoffman VL, Yankey JW, Hillis SL, Wallace RB, Wolinsky FD. Weight and depressive symptom in older adults: direction of influence? J Gerontol Soc Sci. 2007;62(1):43-51. https://doi.org/10.1093/geronb/62.1.S43

9. The journey to age equality. Ramallah: Palestinian Central Bureau of Statistics; 2019 (www.pcbs.gov.ps/portals/_pcbs/PressRelease/Press_En_ElderlyE2019.pdf, accessed 3 November 2019).

10. Chaaya M, Sibai A-M, Roueiheb ZE, Chemaitelly H, Chahine LM, Al-Amin H, et al. Validation of the Arabic version of the short Geriatric Depression Scale (GDS-15). Int Psychogeriatr. 2008;20(3):571-81. https://doi:10.1017/S1041610208006741

11. Vellas B, Villars H, Abellan G, Soto ME, Rolland Y, Guigoz Y. Overview of the MNA - its history and challenges. J Nutr Health Aging. 2006;10(6):456-65. 
12. Lee RD, Nieman DC. Nutritional assessment. New York: McGraw-Hill Higher Education; 2007.

13. Rahman TT, El Gaafary MM. Montreal Cognitive Assessment Arabic version: Reliability and validity prevalence of mild cognitive impairment among elderly attending geriatric clubs in Cairo. Geriatr Gerontol Int. 2009;9(1):54-61. https://doi.org/10.1111/ j.1447-0594.2008.00509.x

14. Hartigan IA. comparative review of the Katz ADL and the Barthel index in assessing the activities of daily living of older people. Int J Older People Nurs. 2007;2(3):204-12. https://doi.org/10.1111/j.1748-3743.2007.00074.x

15. Lawton MP, Brody EM. Assessment of older people: self-maintaining and instrumental activities of daily living. Gerontologist, 1969:9(3):179-86.

16. Richardson RA, Keyes KM, Medina JT, Calvo E. Sociodemographic inequalities in depression among older adults: cross-sectional evidence from 18 countries. Lancet Psychiatry. 2020;7(8):673-81. https://doi.org/10.1016/S2215-0366(20)30151-6

17. Karam GE. Geriatric depression: a brief review. J Med Liban. 2012;60(4):200-6.

18. Laksham KB, Selvaraj R, Kameshvell C. Depression and its determinants among elderly in selected villages of Puducherry - a community-based cross-sectional study. J Family Med Prim Care. 2019;8(1):141. https://doi.org/10.4103/jfmpc.jfmpc_235_18

19. Vanoh D, Shahar S, Yahya HM, Hamid TA. Prevalence and determinants of depressive disorders among community-dwelling older adults: findings from the Towards Useful Aging Study. Int J Gerontol. 2016;10(2):81-5. https://doi.org/10.1016/j. ijge.2016.02.001

20. Stanley P. Risk factors for depressive illness among elderly GOPD attendees at UPTH. IOSR J Dent Med Sci. 2013;5(2):77-86.

21. Tyrovolas S, Lionis C, Zeimbekis A, Bountziouk V, Micheli M, Katsarou A, et al. Increased body mass and depressive symptomatology are associated with hypercholesterolemia, among elderly individuals; results from the MEDIS study. Lipids Health Dis. 2009;8(1):10. https://doi.org/10.1186/1476-511X-8-10

22. Han KT, Kim SJ. Are serum cholesterol levels associated with cognitive impairment and depression in elderly individuals without dementia? A retrospective cohort study in South Korea. Int J Geriatr Psychiatry. 2020 https://doi.org/10.1002/gps.5410

23. Eurelings LS, van Dalen JW, Ter Riet G, Moll van Charante EP, Richard E, van Gool WA, et al. Apathy and depressive symptoms in older people and incident myocardial infarction, stroke, and mortality: a systematic review and meta-analysis of individual participant data. Clin Epidemiol. 2018;10:363-79. https://doi.org/10.2147/CLEP.S150915

24. Engel JH, Siewerdt F, Jackson R, Akobundu U, Wait C, Sahyoun N. Hardiness, depression, and emotional well-being and their association with appetite in older adults. J Am Geriatr Soc. 2011;59(3):482-7. https://doi.org/10.1111/j.1532-5415.2010.03274.X

25. Hawker GA, Gignac MA, Badley E, Davis AM, French MR, Li Y, et al. A longitudinal study to explain the pain-depression link in older adults with osteoarthritis. Arthritis Care Res (Hoboken). 2010;63(10):1382-90. https://doi.org/10.1002/acr.20298

26. Lee JH, Park SK, Ryoo JH, Oh CM, Choi JM, McIntyre RS, et al. U-shaped relationship between depression and body mass index in the Korean adults. Eur Psychiatry. 2017;1(45):72-80. https://doi.org/10.1016/j.eurpsy.2017.05.025

27. Amini S, Shirali S, Jafarirad S, Ehsani H, Mohseni H, Bargard MS. Are lipid profile, body mass index, waist circumference, and blood pressure of depressed elderly patients different from healthy subjects? Int J Prev Med. 2019;10:185. https://doi.org/10.4103/ ijpvm.IJPVM_372_17

28. Wei J, Fan L, Zhang Y, Li S, Partridge J, Claytor L, Sulo S. Association between malnutrition and depression among community-dwelling older Chinese adults. Asia Pac J Public Health. 2018;30(2):107-17. https://doi.org/10.1177/1010539518760632

29. Pérez EC, Lizárraga DCS,Martínez REM. Association between malnutrition and depression in elderly. Nutr Hosp. 2014;29(4):9016. https://doi.org/10.3305/nh.2014.29.4.7228

30. Al-Rasheed R, Alrasheedi R, Al Johani R, Alrashidi H, Almaimany B, Alshalawi B. Malnutrition in elderly and its relation to depression. Int J Community Med Public Health. 2018;5(6):2156-6o. http://doi.org/10.18203/2394-6040.ijcmph20181974

31. Malhotra R, Chan A, Østbye T. Prevalence and correlates of clinically significant depressive symptoms among elderly people in Sri Lanka: findings from a national survey. Int Psychogeriatr. 2009;22(2):227-36. https://doi.org/10.1017/S1041610209990871

32. Chong MY, Tsang HY, Chen CS, Tang TC, Chen CC, Yeh TL. Community study of depression in old age in Taiwan: prevalence, life events and socio-demographic correlates. Br J Psychiatry. 2001;178(1):29-35. https://doi.org/10.1192/bjp.178.1.29

33. Polyakova M, Sonnabend N, Sander C, Mergl R, Schroeter ML, Schroeder J. Prevalence of minor depression in elderly persons with and without mild cognitive impairment: a systematic review. J Affect Disord. 2013;152-154:28-38. https://doi.org/10.1016/j. jad.2013.09.016

34. Richard E, Reitz C, Honig LH, Schupf N, Tang MX, Manly JJ. Late-life depression, mild cognitive impairment, and dementia. JAMA Neurol. 2013;70(3):374-82. https://doi.org/10.1001/jamaneurol.2013.603

35. Mirza SS, Ikram MA, Bos D, Mihaescu R, Hofman A, Tiemeier H. Mild cognitive impairment and risk of depression and anxiety: a population-based study. Alzheimers Dement. 2017;13(2):130-9. https://doi.org/10.1016/j.jalz.2016.06.2361

36. Gao Y, Huang C, Zhao K, Ma L, Qiu X, Zhang L. Depression as a risk factor for dementia and mild cognitive impairment: a meta-analysis of longitudinal studies. Int J Geriatr Psychiatry. 2013;28(5):441-9. https://doi.org/10.1002/gps.3845 